\title{
Seasonal Regression Models for Electricity Consumption Characteristics Analysis
}

\author{
Yusri Syam Akil ${ }^{1,2}$, Hajime Miyauchi ${ }^{1}$ \\ ${ }^{1}$ Department of Frontier Technology for Energy and Devices, Kumamoto University, Kumamoto, Japan \\ ${ }^{2}$ Department of Electrical Engineering, Hasanuddin University, Makassar, Indonesia \\ Email: yusuri@st.cs.kumamoto-u.ac.jp, miyauchi@cs.kumamoto-u.ac.jp
}

Received 2013

\begin{abstract}
This paper presents seasonal regression models of demand to investigate electricity consumption characteristics. Electricity consumption in commercial areas in Japan is analyzed by using meteorological variables, namely temperature and relative humidity. A dummy variable for holidays is also considered. We have developed models for two levels of period to analyze demand characteristics, that is, half year models and seasonal models. Some options for each model are calculated and validated by statistical tests to obtain better models. As results, half year and seasonal models present explicit information about how the variables affect the demand differently for each period. These specific information help in analyzing characteristics of studied commercial demand.
\end{abstract}

Keywords: Commercial Area; Demand Characteristics; Regression Model; Seasons; Relative Humidity; Temperature

\section{Introduction}

In general, electricity consumption analyses such as characteristics investigation and forecasting can provide much information related to the time variance of demand. The result of demand analysis is useful for electric utilities in many aspects, for instance, to manage and control their systems more effective. Therefore, it is valuable to analyze an electricity demand in detail through development of demand models. A number of methods can be used for a demand analysis, and one of them is regression analysis. As a tool, a regression model needs a number of data (dependent and explanation variables). The implementation of proper explanation variables is required to get a good model. As an explanation variable, meteorological parameters such as temperature, humidity, wind speed, and so on, are commonly used and confirmed electricity demand effectively. Prior studies which employed meteorological parameters and regression models for electricity demand can be found in references such as [1-4]. Reference [1] develops a demand model using a stepwise procedure to forecast Spanish daily electricity demand. Reference [2] develops regression equations to analyze electricity consumption for residential area in Hong Kong by using climatic and economic variables. Reference [3] develops the model of electricity consumption for residential area in Bangkok
Metropolis and analyzes effect of climatic and economic factors for demand. Meanwhile, in [4], authors have developed two statistical models for demand in Greece, namely daily and monthly models to forecast demand up to 12 months ahead (mid-term demand).

As electricity demand may differ to time [2,3] and place generally, we have an interest to analyze demand characteristics for commercial area in a typical city in Japan by developing demand models. This study also aims to find the electricity consumption characteristics in Japan. We analyze demand characteristics based on seasonal periods for commercial area in Japan. To achieve the aim, two demand model of two period levels based on different time length, namely half year models (CTEChy1, and CTEChy2) and seasonal models (CTECSM, CTECA, CTECW, and CTECS) are proposed to reveal further demand characteristics by regression analysis. They are developed from an initial model (CTEC) that is derived from all data (whole period) with the same explanation variables and statistical validation processes. In the context of this study, the application of regression approach is effective enough. Beside simple in composing the models, the obtained regression coefficients and statistics contain specific information about the direct relationship between variables and demand. It may be useful to draw a seasonal strategy and to meet demands in maintaining power system performance. 


\section{Data and Initial Demand Model}

To compose demand model for characteristics analysis, three major data are employed, namely a demand in commercial area (Com. T), meteorological data, and holidays. The actual demand data of a typical city in Japan are offered by a utility. It is normalized hourly data from June 2007 to November 2009. Concerning meteorological data, we use data of temperature and relative humidity of a representative city in the same area in Japan where the demand data are collected. They are gathered from Japan Meteorological Agency open website [5].

For characteristics exploration, some figures involved demand and explanation variables are presented in relation to construct model. From histogram and scattered diagram shown in Figure 1, it is obtained that relationship between demand in commercial area Com. $T$ and temperature $T\left({ }^{\circ} \mathrm{C}\right)$ is not linear. Based on this fact, heating degree days $H D D$ and cooling degree days $C D D$ variables which defined in Equations (1) and (2) are used in the composed model $[1,4,6]$.

$$
\begin{aligned}
& H D D=\max \left(T_{\text {ref } 1}-T, 0\right) \\
& C D D=\max \left(T-T_{\text {ref } 2}, 0\right)
\end{aligned}
$$

Concerning $H D D$ and $C D D$, reference value of temperature $\left(\mathrm{T}_{\text {ref }}\right)$ is approximately $18{ }^{\circ} \mathrm{C}$ [1]. However, as electricity demand characteristics may be unique in places, appropriate $T_{\text {ref }}$ for $C D D$ and $H D D$ may lead to optimum results. In this work, four different $T_{\text {ref } 1}=T_{\text {ref } 2}=$ $T_{\text {ref }}$ values $\left(16^{\circ} \mathrm{C}, 17^{\circ} \mathrm{C}, 18^{\circ} \mathrm{C}\right.$, and $19^{\circ} \mathrm{C}$ ) for models are calculated and assessed by statistical tests to get better result. Moreover, to investigate the effect of temperature on the commercial demand, one hour previous temperature values $C D D(-1)$ and $H D D(-1)$ are considered in models as in $[1,4]$.

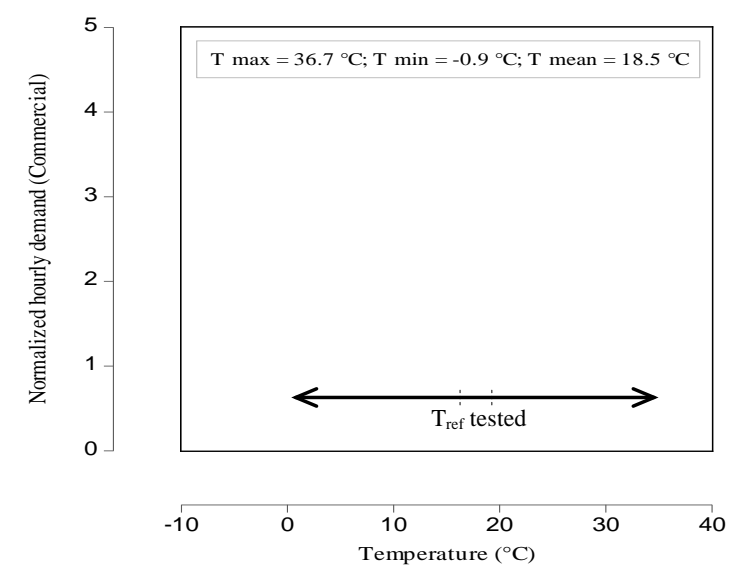

Figure 1. Scattered diagram between Com. $\mathrm{T}$ and temperature.
Figure 2 presents sample values of relative humidity $R H D(\%)$, and demand in one week from $1^{\text {st }}$ (Friday) to $7^{\text {th }}$ (Thursday) August 2008. From the figure, both demand and humidity values fluctuate. However, only the electricity demand has almost similar daily fluctuation. The typical demand fluctuation reaches daily maximum values. Besides, demand in holidays is lower than weekdays.

As an initial demand model, the regression equation for all period is defined as Equation (3). It expresses the normalized hourly demand for all data.

$$
\begin{aligned}
\text { CTEC } & =\alpha_{0}+\alpha_{1} C D D+\alpha_{2} \text { CDD }(-1)+\alpha_{3} H D D \\
& +\alpha_{4} H D D(-1)+\alpha_{5} R H D+\alpha_{6} D H+u_{t}
\end{aligned}
$$

where CTEC is a demand in commercial area. $\alpha_{0}$ is constant, and other $\alpha$ are regression coefficients. $C D D(-1)$ and $H D D(-1)$ are one hour previous data for $C D D$ and $H D D$, respectively. A dummy variable for holidays $D H$ is added in the model. The value $D H=1$ expresses holidays, meanwhile the value 0 (zero) is used for other days (non-holidays). Here, holidays includes not only weekends and national holidays but also non-national holidays such as New Year $\left(2^{\text {nd }}\right.$ and $3^{\text {rd }}$ January) and Obon Festival (13 ${ }^{\text {th }}-16^{\text {th }}$ August).

To avoid serial correlation, an autoregressive component in error term is employed in the regression models. The formula is written in Equation (4) [7]. In this usual method for regression analysis, current value for error term is stated as a number of previous errors [4].

$$
u_{t}=\rho_{1} u_{t-1}+\rho_{2} u_{t-2}+\ldots+\rho_{p} u_{t-p}+\varepsilon_{t}
$$

where $u_{t}$ is error term, $\rho_{p}$ are constants, $p$ is the autoregressive order, and $\varepsilon_{t}$ is a white noise. For the simplicity of models, second order autoregressive error term is used for all models in this study. Models without autoregressive, and with one order autoregressive are also calculated as model options.

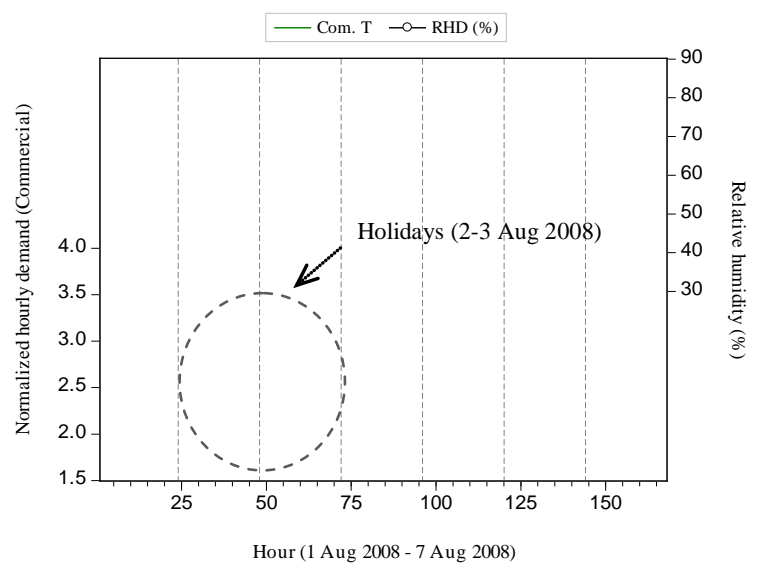

Figure 2. Sample of Com. T variation and humidity for one week in August 2008, and holidays between the period. 


\section{Seasonal Demand Regression Models for Characteristics Analysis}

In this study, to analyze Japanese commercial demand characteristics, demand regression models for two period levels are developed from the initial model. From this, different characteristics for certain periods are investigated. Based on this, we focus on exploring characteristics of demand under two different conditions of temperature and humidity by a half-year model. Then, by constructing seasonal models, we continue to analyze characteristics more specific for each season. Here, the same explanation variables as the initial model are applied for the model of both levels. Similar to [1,4], models are tested by Akaike Information Criterion (AIC) test and Schwarz Criterion (SC) test to decide the best model for each level. The adjusted coefficient of determination $R^{2}$, is also calculated.

\subsection{Proposed Models for Half Year Period}

Seasonal periods can vary for each place in the world. Particularly in Japan, the climate condition is relatively
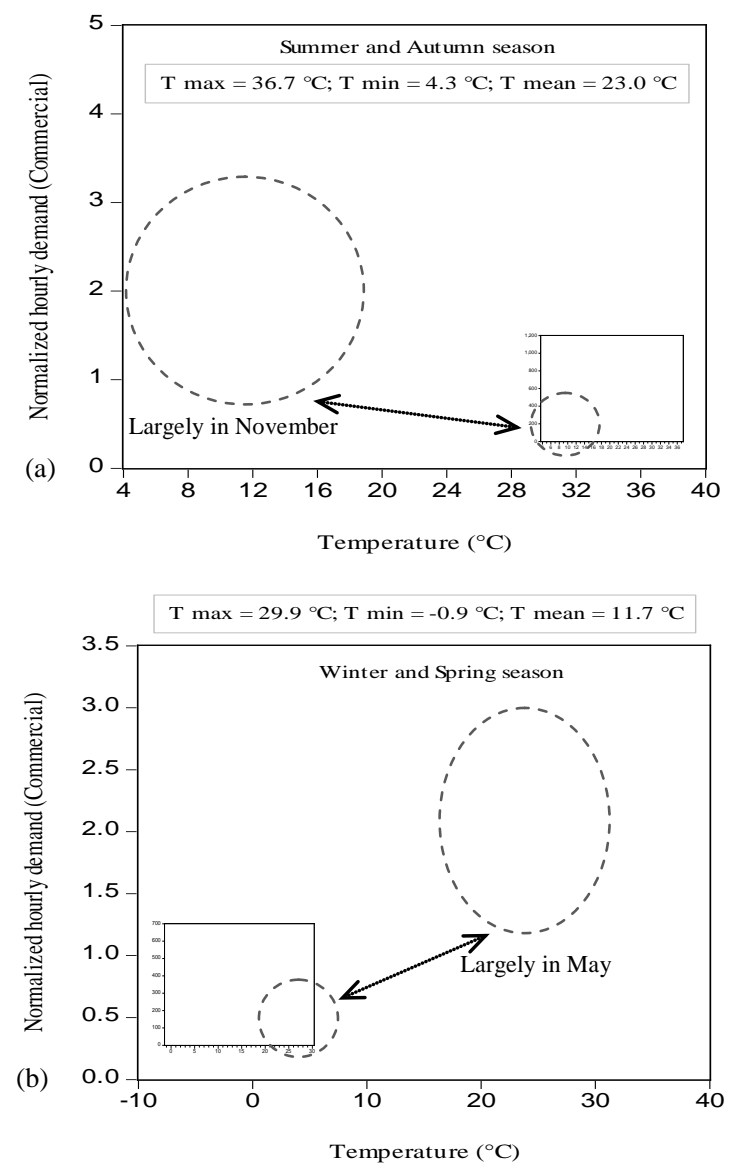

Figure 3. Scattered diagram between Com. $\mathrm{T}$ demand and temperature: (a) half year 1, and (b) half year 2. different from each place. However, summer, autumn, winter, and spring are four seasons occurred in Japan. The summer season starts from June to August, autumn from September to November, winter from December to February, and spring from March to May. On the basis of these seasons, the initial model is developed into two types of half year models, CTEChy1 and CTEChy2. CTEChy1 expresses demand between June and November (summer and autumn), and CTEChy2 expresses demand between December and May (winter and spring). Basically, the conditions of summer and autumn are similar in terms of hot weather in contrast for winter and spring. Therefore, basic characteristics are observed through scattered diagram between demand and temperature for each half year as shown in Figure 3. From the figures, cold temperature in CTEChy1 and hot temperature in CTEChy2 are mainly appeared in November and May, respectively. Histograms of temperature are presented in sub figures in Figure 3. The mean temperature $T_{\text {mean }}$ in November $\left(14.2^{\circ} \mathrm{C}\right)$ is lower than the minimum $T_{\text {ref }}$, meanwhile in May, the $T_{\text {mean }}\left(19.8{ }^{\circ} \mathrm{C}\right)$ is higher than the maximum $T_{\text {ref. }}$. It underlies to use both $C D D$ and $H D D$ as appropriate variables in half year models to explore demand characteristics completely. Other variables (humidity and holidays) and processes are similar to the previous one.

The electricity consumption models for CTEChy1 and CTEChy2 are given in Equations (5) and (6).

$$
\begin{aligned}
\text { CTEChy } 1 & =\hat{\alpha}_{0}+\hat{\alpha}_{1} C D D+\hat{\alpha}_{2} C D D(-1)+\hat{\alpha}_{3} H D D \\
& +\hat{\alpha}_{4} H D D(-1)+\hat{\alpha}_{5} R H D+\hat{\alpha}_{6} D H+u_{t} \\
\text { CTEChy2 } & =\hat{\alpha}_{0}+\hat{\alpha}_{1} C D D+\hat{\alpha}_{2} C D D(-1)+\hat{\alpha}_{3} H D D \\
& +\hat{\alpha}_{4} H D D(-1)+\hat{\alpha}_{5} R H D+\hat{\alpha}_{6} D H+u_{t}
\end{aligned}
$$

where CTEChy1 and CTEChy2 are demand in commercial area for half year 1 and 2 periods, respectively. $\quad \hat{\alpha}_{0}$ is constant, and other $\hat{\alpha}$ are regression coefficients. Other variables are the same as ones in the initial model, Equation (3).

However, considering natural variation of the temperature, two other different half year models which expressed demand between May and October, and between November and April are calculated as well. It means in this category, all $T_{\text {mean }}$ (each month) in the period of CTEChy1 and CTEChy2 become above and below $T_{\text {ref }}$, respectively (figure not shown). Due to only a small part of temperature values remained below or above $T_{\text {ref }}$ in the periods, it is proper to implement only $C D D$ in CTEChy1, or HDD in CTEChy2. Next, all results are compared each other to get better result. 


\subsection{Proposed Models for Seasonal Demand Models}

With regard to the effort to reveal demand characteristics, the preceding models are developed according to the seasons. Four electricity consumption models, namely summer (CTECSM), autumn (CTECA), winter (CTECW), and spring model (CTECS) are composed.

Based on the seasons, November and May are months in autumn and spring season, respectively. Therefore, we use two temperature variables (CDD and HDD) to compose autumn and spring models (CTECA and CTECS). For other two models (CTECSM and CTECW), both in their periods contain a few temperature values below $\left(\mathrm{T}_{\min }=13.4{ }^{\circ} \mathrm{C}\right)$ or above $\left(\mathrm{T}_{\max }=20.8^{\circ} \mathrm{C}\right)$ of $T_{\text {ref }}$ range. However, we consider only dominant temperature to compose CTECSM and CTECW models for simplification. The range of temperature for each season is shown in Figure 4.

The regression equations for each seasonal model are defined in Equations (7)-(10).

$$
\begin{aligned}
\text { CTECSM } & =\hat{\beta}_{0}+\hat{\beta}_{1} C D D+\hat{\beta}_{2} C D D(-1)+\hat{\beta}_{3} R H D \\
& +\hat{\beta}_{4} D H+u_{t} \\
\text { CTECA } & =\hat{\beta}_{0}+\hat{\beta}_{1} C D D+\hat{\beta}_{2} C D D(-1)+\hat{\beta}_{3} H D D \\
& +\hat{\beta}_{4} H D D(-1)+\hat{\beta}_{5} R H D+\hat{\beta}_{6} D H+u_{t} \\
\text { CTECW } & =\hat{\beta}_{0}+\hat{\beta}_{1} H D D+\hat{\beta}_{2} H D D(-1)+\hat{\beta}_{3} R H D \\
& +\hat{\beta}_{4} D H+u_{t} \\
C T E C S & =\hat{\beta}_{0}+\hat{\beta}_{1} C D D+\hat{\beta}_{2} C D D(-1)+\hat{\beta}_{3} H D D \\
& +\hat{\beta}_{4} H D D(-1)+\hat{\beta}_{5} R H D+\hat{\beta}_{6} D H+u_{t}
\end{aligned}
$$

where CTECSM, CTECA, CTECW, and CTECS show demand in summer, autumn, winter, and spring season, respectively. The $\hat{\beta}_{0}$ is constant, and other $\hat{\beta}$ values are

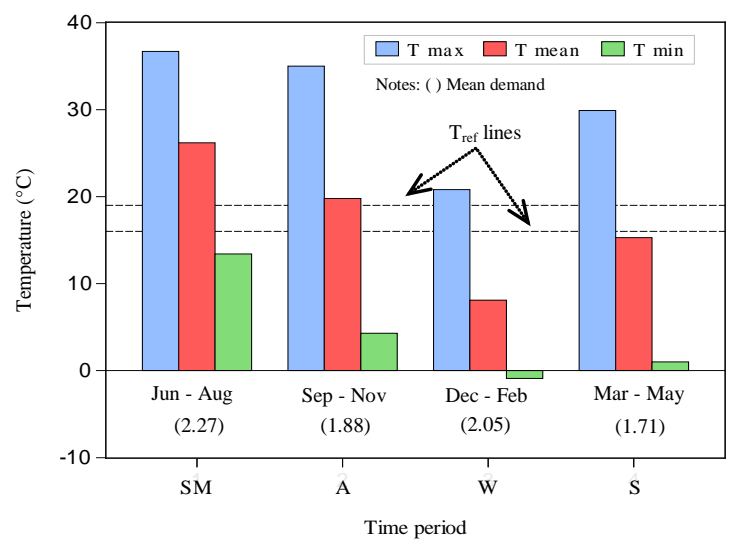

Figure 4. Comparison of temperature limits for each season: SM = summer, $\mathrm{A}=$ autumn, $\mathrm{W}=$ winter, $\mathrm{S}=$ spring. regression coefficients. The other variables are the same as ones in the previous model, Equation (3).

\section{Result and Analysis}

\subsection{Demand Characteristics with All Period}

The regression coefficients and results of the statistical tests for the initial model of commercial area is listed in Table 1. From tested $T_{r e f}\left(T_{r e f 1}=T_{r e f 2}=T_{r e f}\right)$ in the model, $19{ }^{\circ} \mathrm{C}$ gives better result from the assessment by $A I C$ test, $S C$ test, and $R^{2}$. The results listed in Tables $\mathbf{1}$ is the results for $T_{r e f}=19^{\circ} \mathrm{C}$. In this study, EViews 6 [8] is used to compute the model equations.

As presented in Table 1, $R^{2}$ and $R^{2}$, are almost $90 \%$. It indicates that used variables can explain the commercial demand well. The application of $5 \%$ significance level for $p$-value gives that all explanation variables are significant. The value of 0 for Prob. (F-Statistics) indicates at least one of the applied variables influence the demand. Besides, Durbin-Watson (D-W) statistic implies the initial model does not contain serial correlation because its value is around 2 . To confirm the nonexistence of heteroskedasticity problem, corrected standard errors regression is performed [7]. The related adjusted standard errors are listed in Table 1 as well.

Among coefficient values for meteorological variables, $C D D$ (0.0410) has the highest influence to the demand, followed by $H D D, C D D(-1), H D D(-1)$, and $R H D$. As temperature functions, the coefficient ratio of $C D D$ to $\operatorname{HDD}\left(\alpha_{1} / \alpha_{3}\right)$ [9] is around 2.67. The commercial demand can increase easier under hot temperature than under cold temperature. Likewise for influence of one hour previous temperature, $C D D(-1)$ affects the demand around 4.03 times of $H D D(-1)$. For humidity, it has the lowest influence to demand. As coefficient for dummy holidays $\alpha_{6}$ is negative, demand is lower in holidays than in non-holidays.

Table 1. Regression results for all period demand model.

\begin{tabular}{ccccc}
\hline \multirow{2}{*}{$\begin{array}{c}\text { Expl. } \\
\text { Variable }\end{array}$} & \multicolumn{4}{c}{ All Period Demand Model } \\
\cline { 2 - 5 } & Coef. & t-statistic & $\begin{array}{c}\text { Prob. } \\
(p \text {-value })\end{array}$ & $\begin{array}{c}\text { Adjs. } \\
\text { standard error }\end{array}$ \\
\cline { 2 - 5 }$\alpha_{0}$ & 1.7456 & 81.93 & 0 & 0.0213 \\
\hline CDD & 0.0410 & 30.88 & 0 & 0.0013 \\
\hline CDD(-1) & 0.0125 & 13.61 & 0 & 0.0009 \\
\hline HDD & 0.0153 & 24.08 & 0 & 0.0006 \\
\hline HDD(-1) & 0.0031 & 5.44 & 0 & 0.0005 \\
\hline RHD & 0.0011 & 11.96 & 0 & $9.7 \mathrm{E}-05$ \\
\hline DH & -0.1744 & -60.58 & 0 & 0.0028 \\
\hline
\end{tabular}

Note: $\mathrm{R}^{2}=0.8988 ; \mathrm{R}^{2}=0.8988$; SE Reg. $=0.1814 ; \mathrm{D}-\mathrm{W}=2.1230$;

Prob. $($ F-Stat. $)=0.0000 ;$ AIC $=-0.5752 ; \mathrm{SC}=-0.5719$ 


\subsection{Demand Characteristics with Half Year Models}

Half year models started from May to October (CTEChy1) and from November to April (CTEChy2) are obtained. Naturally, as period of CTEChy1 is hot season, the temperature in CTEChy1 is higher than CTEChy2. Moreover, all monthly average values of humidity $\left(\mathrm{RHD}_{\text {mean }}\right)$ in the period of CTEChy1 tend to higher than in the period of CTEChy2 as shown in Figure 5.

The best results for half year models which are specified with second order autoregressive error term are presented in Tables 2 and 3. In Table 2, where $19{ }^{\circ} \mathrm{C}$ and $16{ }^{\circ} \mathrm{C}$ are optimum $T_{\text {ref }}$ values for CDD in CTEChy1, and $H D D$ in CTEChy2 model, respectively. The statistical

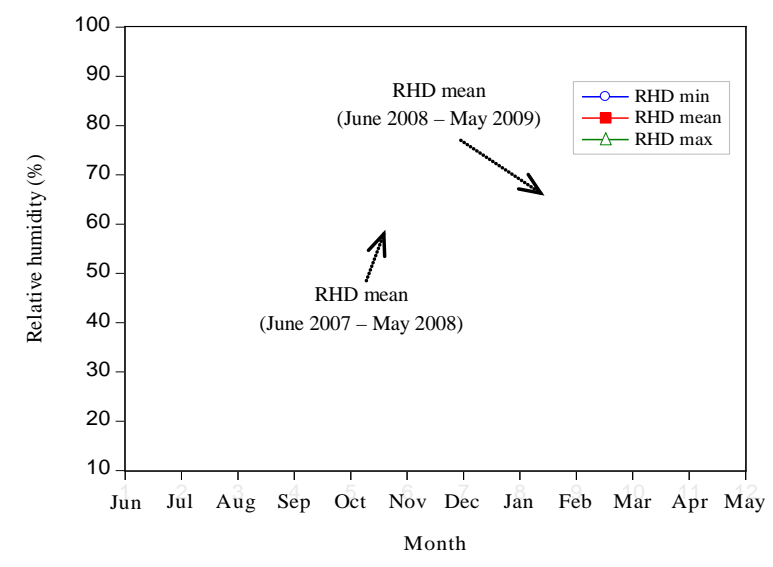

Figure 5. Variation of humidity values for each month from

June 2000 to May 2007

Table 2. Regression coefficients of the half year models.

\begin{tabular}{|c|c|c|c|c|}
\hline \multirow{3}{*}{$\begin{array}{c}\text { Expl. } \\
\text { Variable }\end{array}$} & \multicolumn{4}{|c|}{ Half Year Demand Model } \\
\hline & \multicolumn{2}{|c|}{ CTEChy1 $\left(\mathrm{T}_{\mathrm{ref}}=19^{\circ} \mathrm{C}\right)$} & \multicolumn{2}{|c|}{ CTEChy2 $\left(\mathrm{T}_{\mathrm{ref}}=16^{\circ} \mathrm{C}\right)$} \\
\hline & Coef. & $\begin{array}{c}\text { Prob. } \\
(p \text {-value })\end{array}$ & Coef. & $\begin{array}{c}\text { Prob. } \\
\text { (p-value) }\end{array}$ \\
\hline \multirow[b]{2}{*}{$\hat{\alpha}_{0}$} & 1.6260 & 0 & 1.8137 & 0 \\
\hline & $(48.26)$ & 0.0336* & (74.35) & $0.0243^{*}$ \\
\hline \multirow{2}{*}{ CDD } & 0.0468 & 0 & & \\
\hline & $(31.75)$ & $0.0014^{*}$ & & \\
\hline \multirow{2}{*}{$\mathrm{CDD}(-1)$} & 0.0110 & 0 & & \\
\hline & $(11.84)$ & $0.0009 *$ & & \\
\hline \multirow{2}{*}{ HDD } & & & 0.0178 & 0 \\
\hline & & & $(24.01)$ & $0.0007 *$ \\
\hline \multirow{2}{*}{$\operatorname{HDD}(-1)$} & & & 0.0030 & 0 \\
\hline & & & (4.61) & $0.0006^{*}$ \\
\hline \multirow{2}{*}{ RHD } & 0.0030 & 0 & $8.00 \mathrm{E}-05$ & 0.4484 \\
\hline & $(16.92)$ & $0.0001^{*}$ & $(0.75)$ & $0.0001 *$ \\
\hline \multirow{2}{*}{$\mathrm{DH}$} & -0.1870 & 0 & -0.1562 & 0 \\
\hline & $(-43.16)$ & 0.0043* & $(-44.29)$ & $0.0035^{*}$ \\
\hline
\end{tabular}

Notes: CTEChy1 = from May to October; CTEChy2 = from November to April; () t-statistic; *adjs. standard error; _not significant related to its variable
Table 3. Regression statistics of the half year models.

\begin{tabular}{ccccccc}
\hline $\begin{array}{c}\text { Half Year } \\
\text { Model }\end{array}$ & $\mathrm{R}^{2}$ & $\mathrm{R}^{2}$, & $\begin{array}{c}\text { SE } \\
\text { Reg. }\end{array}$ & D-W & AIC & SC \\
\hline CTEChy1 & 0.9089 & 0.9088 & 0.1978 & 2.1343 & -0.4024 & -0.3982 \\
\hline CTEChy2 & 0.8556 & 0.8555 & 0.1524 & 2.0946 & -0.9231 & -0.9178 \\
\hline
\end{tabular}

Note: Prob. (F-Stat.) both CTEChy1 and CTEChy2 = 0.0000;

Without RHD in CTEChy2 model, $\mathrm{R}^{2}$, $=85.55 \%$

results in Table 3 and Table 2 show both models validated well. By separating the period, the value of $R^{2}$, increases slightly in CTEChy1 (90.88\%) and decreases in CTEChy2 (85.55\%) when we compared with $R^{2}$, value of CTEC model (89.88\%). CTEChy1 has higher degree of fitness than CTEChy2 model.

For constant values $\hat{\alpha}_{0}$, it is obtained larger in CTEChy2 (1.8137) than in CTEChy1 (1.6260). The constant value is associated with base demand. Among meteorological variables in CTEChy1 and CTEChy2 models as in Table 2, CDD (0.0468) and HDD (0.0178) have the largest effect to the demand, respectively. However, comparing these coefficient values (CDD in CTEChy1, and HDD in CTEChy2), the demand responses higher in hot temperature than in cold temperature. Concerning humidity, this variable gives the lowest influence, and affects the demand only in CTEChy1 period (high humidity). The elimination of non-significance variable $R H D$ in CTEChy2 is proper as it gives almost the same results. The dummy variable $D H$ shows decrease of the commercial demand in holidays, but in different amount for both half year models.

\subsection{Demand Characteristics with Seasonal Models}

Tables 4 and 5 present best regression results with optimum $T_{\text {ref }}$ for each seasonal model. Optimum $T_{r e f}$ is $19^{\circ} \mathrm{C}$ for summer and autumn models, meanwhile $16{ }^{\circ} \mathrm{C}$ for other two models. The $T_{\text {ref }}$ value tends to high under hot seasons and vice versa. From the results, the value $R^{2}$, ranges between $81.34 \%$ and $90.19 \%$. The models under hot seasons (CTECSM and CTECA) have higher $R^{2}$, values than others under cold seasons (CTECW and CTECS). The highest $R^{2}$, is in summer, and the lowest is

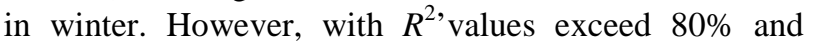
three of them above $86 \%$, all models have quite good fitness degree. Next, among implemented variables in the seasonal models, $C D D(-1)$ and $H D D(-1)$ in spring (CTECS) are not significant at 5\% significance level. As spring is not so hot or so cold (comfortable season), it may related to the non-significance of the one hour previous temperature $(\operatorname{CDD}(-1)$ and $\operatorname{HDD}(-1))$ to demand. For simplification, both $C D D(-1)$ and $H D D(-1)$ in CTECS model can be eliminated without influence on regression results. 
Table 4. Regression coefficients of the seasonal models with optimum $\mathbf{T}_{\text {ref }}$.

\begin{tabular}{|c|c|c|c|c|}
\hline \multirow{3}{*}{$\begin{array}{c}\text { Expl. } \\
\text { Variable }\end{array}$} & \multicolumn{4}{|c|}{ Seasonal Demand Model } \\
\hline & \multicolumn{2}{|c|}{$\operatorname{CTECSM}\left(\mathrm{T}_{\mathrm{ref}}=19^{\circ} \mathrm{C}\right)$} & \multicolumn{2}{|c|}{ CTECA $\left(\mathrm{T}_{\mathrm{ref}}=19^{\circ} \mathrm{C}\right)$} \\
\hline & Coef. & $\begin{array}{c}\text { Prob. } \\
(p \text {-value })\end{array}$ & Coef. & $\begin{array}{c}\text { Prob. } \\
(p \text {-value })\end{array}$ \\
\hline \multirow[b]{2}{*}{$\hat{\beta}_{0}$} & 1.6009 & 0 & 1.6252 & 0 \\
\hline & (27.79) & $0.0576^{*}$ & $(49.58)$ & $0.0327^{*}$ \\
\hline \multirow{2}{*}{ CDD } & 0.0495 & 0 & 0.0535 & 0 \\
\hline & (24.09) & $0.0020^{*}$ & (19.69) & $0.0027^{*}$ \\
\hline \multirow{2}{*}{$\operatorname{CDD}(-1)$} & 0.0095 & 0 & 0.0190 & 0 \\
\hline & $(7.75)$ & $0.0012 *$ & $(11.15)$ & $0.0017^{*}$ \\
\hline \multirow{2}{*}{ HDD } & & & 0.0118 & 0 \\
\hline & & & $(10.64)$ & $0.0011^{*}$ \\
\hline \multirow{2}{*}{$\operatorname{HDD}(-1)$} & & & 0.0058 & 0 \\
\hline & & & (5.59) & $0.0010^{*}$ \\
\hline \multirow{2}{*}{ RHD } & 0.0044 & 0 & 0.0009 & 0 \\
\hline & $(13.92)$ & $0.0003 *$ & $(5.09)$ & $0.0001^{*}$ \\
\hline \multirow{2}{*}{ DH } & -0.2231 & 0 & -0.1515 & 0 \\
\hline & $(-34.28)$ & 0.0065* & $(-31.82)$ & $0.0047^{*}$ \\
\hline \multirow{3}{*}{$\begin{array}{c}\text { Expl. } \\
\text { Variable }\end{array}$} & \multicolumn{4}{|c|}{ Seasonal Demand Model } \\
\hline & \multicolumn{2}{|c|}{ CTECW $\left(\mathrm{T}_{\mathrm{ref}}=16^{\circ} \mathrm{C}\right)$} & \multicolumn{2}{|c|}{$\operatorname{CTECS}\left(\mathrm{T}_{\mathrm{ref}}=16^{\circ} \mathrm{C}\right)$} \\
\hline & Coef. & $\begin{array}{c}\text { Prob. } \\
(p \text {-value })\end{array}$ & Coef. & $\begin{array}{c}\text { Prob. } \\
\text { (p-value })\end{array}$ \\
\hline \multirow{2}{*}{$\hat{\beta}_{0}$} & 2.0090 & 0 & 1.6157 & 0 \\
\hline & (59.03) & $0.0340 *$ & $(49.95)$ & $0.0323 *$ \\
\hline \multirow{2}{*}{ CDD } & & & 0.0090 & 0 \\
\hline & & & $(7.25)$ & $0.0012 *$ \\
\hline \multirow{2}{*}{$\mathrm{CDD}(-1)$} & & & 0.0010 & $\underline{0.3360}$ \\
\hline & & & $(0.96)$ & $0.0010^{*}$ \\
\hline \multirow{2}{*}{ HDD } & 0.0162 & 0 & 0.0194 & 0 \\
\hline & (14.27) & 0.0011* & $(19.80)$ & $0.0009^{*}$ \\
\hline \multirow{2}{*}{$\operatorname{HDD}(-1)$} & 0.0023 & 0.0167 & 0.0008 & 0.4237 \\
\hline & (2.39) & 0.0009* & $(0.80)$ & $0.0010^{*}$ \\
\hline \multirow{2}{*}{ RHD } & -0.0005 & 0.0032 & 0.0012 & 0 \\
\hline & $(-2.95)$ & 0.0001* & $(9.48)$ & $0.0001^{*}$ \\
\hline \multirow{2}{*}{ DH } & -0.1813 & 0 & -0.1308 & 0 \\
\hline & $(-29.65)$ & 0.0061* & $(-30.32)$ & $0.0043^{*}$ \\
\hline
\end{tabular}

Notes: () t-statistic; *adjs. standard error; _ not significant related to its variable

Table 5. Regression statistics of the four seasonal models.

\begin{tabular}{lcccc}
\hline \multirow{2}{*}{ Reg. Statistics } & \multicolumn{4}{c}{ Seasonal Model } \\
\cline { 2 - 5 } & CTECSM & CTECA & CTECW & CTECS \\
\hline $\mathrm{R}^{2}$ & 0.9020 & 0.8986 & 0.8136 & 0.8605 \\
\hline $\mathrm{R}^{2}$ & 0.9019 & 0.8984 & 0.8134 & 0.8602 \\
\hline $\mathrm{D}-\mathrm{W}$ & 2.1626 & 2.0944 & 2.0871 & 2.1188 \\
\hline SE Reg. & 0.2133 & 0.1719 & 0.1748 & 0.1237 \\
\hline Prob. (F-Stat.) & 0.0000 & 0.0000 & 0.0000 & 0.0000 \\
\hline AIC & -0.2507 & -0.6813 & -0.6476 & -1.3390 \\
\hline SC & -0.2435 & -0.6719 & -0.6374 & -1.3260 \\
\hline
\end{tabular}

Notes: Without CDD(-1) and HDD(-1) in CTECS model

$\mathrm{R}^{2,}=86.00 \% ; \mathrm{R}^{2,}=86.09 \%(2008) ; \mathrm{R}^{2}=85.86 \%(2009)$
From analysis of actual data, the highest normalized mean demand is found in summer, followed by winter, autumn, and spring. The use of cooling or heating equipments can contribute to the situation.

The obtained constant values $\hat{\beta}_{0}$ which represent base demand are larger in winter (2.0090) than in summer (1.6009). Meanwhile, base demand for autumn (1.6252) and spring (1.6157) are between the values in summer and winter. As lighting equipments may contribute to base demand, daylight duration is roughly 12 hours in these periods. For $\hat{\beta}$ coefficients which quantify effect of variables to demands, they show meteorological variables in summer (CDD, $\mathrm{CDD}(-1)$, RHD) have higher influence to demand than the variables in winter (HDD, $\mathrm{HDD}(-1)$, RHD). In summer, the highest coefficient is $C D D$ (0.0495), meanwhile in winter is $H D D(0.0162)$. Next, for seasons without severe temperature, coefficient value of $C D D$ is found larger than $H D D$ in autumn (CTECA), and on the contrary in spring (CTECS). It implies dominant temperature is $C D D$ in autumn and $H D D$ in spring. However, compared between the dominant temperature functions, $C D D(0.0535)$ is obtained higher in autumn than $H D D(0.0194)$ in spring. As driver factors, in summer, not only temperature (in terms of hot) is high for all months but also humidity. On the other hand, in winter, only temperature is high (in terms of cold). Summer and winter peak periods occur in August and January in Japan, respectively. Humidity $R H D$ may reduce from the models except for summer. For holidays, it gives the highest effect on the demand in summer and on the contrary in spring.

\section{Conclusions}

This paper presents seasonal regression models to analyze demand characteristics in commercial area (Com. $\mathrm{T}$ ) in a typical city in Japan. To carry out the analysis, meteorological and holidays variables are considered as factors affect the electricity consumption. Two models are developed depending on the periods, namely half year (CTEChy1, and CTEChy2) and seasonal models (CTECSM, CTECA, CTECW, and CTECS). As results, more specific characteristics can be revealed by the proposed models by validating many statistical tests. The obtained optimum $T_{\text {ref }}$ for CTEChy1, CTECSM, and CTECA models are $19{ }^{\circ} \mathrm{C}$, and other three models are $16{ }^{\circ} \mathrm{C}$. It implies that $T_{\text {ref }}$ for the demand may change by periods. They have quite good fitness degree shown by the adjusted coefficient of determination $R^{2}$, which varies around $85.55 \%$ to $90.88 \%$ for half year models, and $81.34 \%$ to $90.19 \%$ for seasonal models. It reflects that variables affect the demand differently for each period. The $R^{2}$, values are relatively high in CTEChy1 for half 
year model, and in CTECSM (summer) and CTECA (autumn) for seasonal models. Implemented variables can explain commercial demand optimally in hot weather rather than in cold weather. The base demand is relatively higher in the cold than in hot season. Among meteorological variables, $C D D$ and $H D D$ are the most significant variables. For non-significance variables, elimination of them results in simplified models which may reduce computation burden. Next, in holidays, demand decreses in all periods but in difference amount.

The presented results can give more insight especially when demand characteristics in seasonal levels are required. It is usefull in quantifying influence of variables on demand at certain area or period, and in understanding demand situation more detail.

\section{REFERENCES}

[1] A. Pardo, V. Meneu and E. Valor, "Temperature and Seasonality Influences on Spanish Electricity Load,” Energy Economics, Vol. 24, 2002, pp. 55-70. doi: 10.1016/S0140-9883(01)00082-2

[2] J. C. Lam, "Climatic and Economic Influences on Residential Electricity Consumption,” Energy Convers. Mgmt, Vol. 39, No. 7, 1998, pp. 623-629. doi: 10.1016/S0196-8904(97)10008-5

[3] K. Wangpattarapong, S. Maneewan, N. Ketjoy and W. Rakwichian, "The Impacts of Climatic and Economic Factors on Residential Electricity Consumption of Bangkok Metropolis,” Energy and Buildings, Vol. 40, 2008, pp. 1419-1425. doi: 10.1016/j.enbuild.2008.01.006

[4] S. Mirasgedis, Y. Sarafidis, E. Georgopoulou, D. P. Lalas, M. Moschovits, F. Karagiannis and D. Papakonstantinou, "Models for Mid-Term Electricity Demand Forecasting Incorporating Weather Influences,” Energy, Vol. 31, 2006, pp. 208-227. doi: 10.1016/j.energy.2005.02.016

[5] Japan Meteorological Agency (JMA). http://www.jma.go.jp/jma/indexe.html

[6] B. E. Psiloglou, C. Giannakopoulos, S. Majithia and M. Petrakis, "Factors Affecting Electricity Demand in Athens, Greece and London, UK: A Comparative Assessment,” Energy, Vol. 34, 2009, pp. 1855-1863. doi: 10.1016/j.energy.2009.07.033

[7] R. Startz, "EViews Illustrated for Version 6," 1st Edition, Quantitative Micro Software, LLC, 2007.

[8] EViews. http://www.eviews.com

[9] D. J. Sailor and J. R. Muñoz, "Sensitivity of Electricity and Natural Gas Consumption to Climate in the U.S.A.-Methodology and Results for Eight States," Energy, Vol. 22, No. 10, 1997, pp. 987-998. doi: 10.1016/S0360-5442(97)00034-0 